\title{
PENENTUAN SIFAT MAGNETIK DAN MORFOLOGI PARTIKEL MAGNETIK PASIR BESI PANTAI ARTA PARIAMAN SUMATERA BARAT
}

\author{
Ayu Wulandhari", Erwin \\ Jurusan Fisika Fakultas Matematika dan Ilmu Pengetahuan Alam Universitas Riau \\ *E-mail korespondensi: awulandhari80@gmail.com
}

\begin{abstract}
Magnetic properties and particle size of iron sand of Arta Beach Pariaman of West Sumatera have been studied. Magnetic and non-magnetic particles of iron sand were separated using the Iron Sand Separator (ISS) before advanced processed by Ball Milling which was based on variaties of time such as 30 hours, 60 hours, and 90 hours. Then Ball Milling process was continued for another 30 hours on the sample of 90 hours milled using smaller size of balls that was $0,6 \mathrm{~cm}$ in diameter. Magnetic and non- magnetic particles were separated using Neodymium Iron Boron (NdFeB) magnet. Magnetic properties such as magnetic susceptibility and mass susceptibility were determined using a PS-2162 Pasco Magnetic Probe based on a solenoid wind with 2000 turns, length of $10 \mathrm{~cm}$, and diameter $3 \mathrm{~cm}$. The composition of the iron sand was identified using $X$-Ray Fluoorescence (XRF). The shape and the size of magnetic particles were determined by Scanning Electron Microscope (SEM). The results of this research showed that the particles size obtained were $935 \mathrm{~nm}$ for 90 hours Ball Milling time and sizes in the range of $519 \mathrm{~nm}$ for Ball Milling time 120 hours 190 hours +30 hours. The iron sand particles have irregularized shape for each time a Ball Milling. The content of samples especially, magnetic particle $(\mathrm{Fe})$ before and after being processed by Ball Milling for 120 hours are $6.118 \%$ and $67.746 \%$. Mass susceptibility increased from $27955,7 \times 10^{-8} \mathrm{~m}^{3} / \mathrm{kg}$ to $31478,5 \times 10^{-8} \mathrm{~m}^{3} / \mathrm{kg}$ for milling time of 90 hours and 120 hours. These values are in the Ilminite mineral interval (46-80000) $\times 10^{-8} \mathrm{~m}^{3} / \mathrm{kg}$.
\end{abstract}

Keywords: Iron sand, Scanning Electron Microscope (SEM), Ball milling, Iron sand separator, Xray fluorescence

\begin{abstract}
ABSTRAK
Telah dilakukan penelitian tentang sifat magnetik dan ukuran partikel dari pasir besi pantai Arta Pariaman Sumatera Barat menggunakan metode Ball Milling. Sampel pasir besi dipisahkan menggunakan Iron Sand Separator (ISS) sebelum dilakukannya proses penghancuran menggunakan Ball Milling dengan variasi waktu 30 jam, 60 jam, dan 90 jam, kemudian dilakukan Ball Milling lanjutan selama 30 jam pada sampel hasil Ball Milling 90 jam dengan ukuran bola yang diperkecil sebesar 0,6 cm. Untuk pemisahan antara partikel magnetik dan non-magnetik pada hasil Ball Milling menggunakan magnet batang Niodinium Iron Boron (NdFeB). Sifat magnetik seperti suseptibilitas magnetik dan suseptibilitas massa dapat diketahui dengan menggunakan sensor Pasco Magnetic Probe PS-2162 dengan kumparan solenoid 2000 lilitan, panjang $10 \mathrm{~cm}$, dan diameter $3 \mathrm{~cm}$, sedangkan komposisi dari pasir besi menggunakan X-Ray Fluorescence (XRF). Ukuran dan bentuk partikel magnetik ditentukan dengan Scanning Electtron Microscope (SEM). Dari penelitian ini hasil ukuran partikel yang didapat sebesar $935 \mathrm{~nm}$ untuk waktu Ball Milling 90 jam dan ukuran dalam rentang sebesar $519 \mathrm{~nm}$ untuk waktu Ball Milling 120 jam/90 jam + 30 jam, Bentuk partikel pasir besi hampir bulat untuk masing-masing waktu Ball Milling. Kandungan pasir besi sebelum dan sesudah di Ball Milling selama 120 jam yaitu $6,118 \%$ dan $67,746 \%$. Suseptibilitas massa meningkat dari $27955,7 \times 10^{-8} \mathrm{~m}^{\mathrm{a}} / \mathrm{Kg}$ menjadi $31478,5 \times 10^{-8} \mathrm{~m}^{\mathrm{a}} / \mathrm{Kg}$. Nilai ini berada dalam interval mineral Ilminite (46$80000) \times 10^{-9} \mathrm{~m}^{2} / \mathrm{kg}$.
\end{abstract}

Kata kunci: Pasir besi, Scanning Electron Microscope (SEM), Ball milling, Iron sand separator, $\mathrm{X}$-ray fluorescence

Diterima 22-07-2019 | Disetujui 15-01-2019| Dipublikasi 31-03-2020 


\section{PENDAHULUAN}

Besi merupakan logam kedua yang paling banyak di bumi dan terdapat dalam bentuk endapan. Endapan besi yang terdapat dalam batuan sedimen berupa pasir dikenal sebagai pasir besi. Pantai barat pulau Sumatera khususnya Pantai Pariaman (Pantai Arta) memiliki pasir besi yang jumlahnya melimpah yang menjadi daya tarik secara ekonomi untuk dikembangkan menjadi produk yang lebih bernilai dan berdaya guna [1]. Pasir besi yang telah dipisahkan dari material non magnetik banyak digunakan sebagai bahan dalam pabrik baja, bahan peleburan besi dan juga campuran semen. Pasir besi ini memiliki ciri-ciri warna kehitaman dan banyak ditemukan di berbagai pantai, sungai, dan pegunungan [2]. Pasir besi mengandung partikel magnetite $\left(\mathrm{Fe}_{3} \mathrm{O}_{4}\right)$, hematite $\left(\alpha-\mathrm{Fe}_{2} \mathrm{O}_{3}\right)$, dan maghemite $\left(\gamma-\mathrm{Fe}_{2} \mathrm{O}_{3}\right)$ yang mempunyai potensi besar dalam pengembangan industri [3].

Salah satu kajian dari pasir besi adalah sifat nanopartikel magnetik tentang karakteristik magnetiknya terhadap medan magnet luar. Nanopartikel magnetik merupakan kelas dari partikular material rekayasa yang ukurannya $<100 \mathrm{~nm}$ yang dapat dimanipulasi dibawah pengaruh medan magnet eksternal. Nanopartikel magnetik umumnya terdiri dari unsur-unsur magnetik, seperti besi, nikel, dan oksida [4]. Partikel pasir besi dalam ukuran nanometer memiliki sifat yang unik yang disebut superparamagnetik. Partikel superparamagnetik memiliki nilai koersivitas yang kecil dan memiliki nilai momen magnetik yang besar [5]. Sifat magnetik dari nanopartikel dapat di modifikasi yang aplikasinya sangat luas seperti media penyimpan data [6], sensor magnetik [7], bidang bioengineering yaitu untuk pengiriman obat ke sasaran terapi tumor [8], serta sebagai material penjernih air [9].

Metode untuk mensintesis nanopartikel magnetik diantaranya yaitu ada metode kimia, fisika, dan biologi. Khususnya untuk metode fisika dilakukan dengan metode ball milling, dimana terjadinya tumbukan antara pasir besi dan bola-bola di dalam ball milling sehingga menyebabkan pasir besi pecah menjadi bagian yang sangat kecil mencapai ukuran mikrometer ( $\mu m)$ hingga nanometer $(\mathrm{nm})$. Penggilingan ini bertujuan untuk memperoleh partikel bahan magnet yang memiliki domain magnetik tunggal sebelum diolah lebih lanjut menjadi barang komoditi [10].

Penelitian ini akan mengidentifikasi sifat magnetik serta melihat ukuran dan bentuk partikel pasir besi yang berasal dari Pantai Arta, Pariaman, Sumatera Barat.

\section{METODE PENELITIAN}

Pada penelitian ini akan dilakukan analisa karakterisasi terhadap pasir besi Pantai Arta Pariaman Sumatera Barat yang sudah dipisahkan menggunakan Iron Sand Separator (ISS) dan melalui proses penghancuran menggunakan Ball Milling. Sampel pasir besi yang digunakan merupakan proses Ball Milling ada 2 tahap yaitu tahap 1 (konsentrat 1) dengan waktu penggilingan $30 \mathrm{jam}, 60 \mathrm{jam}$, dan 90 jam dengan ukuran bola penumbuk 1,6 $\mathrm{cm}$ kemudian Ball Milling tahap 2 (konsentrat 2) yang dilakukan pada sampel 90 jam selama 30 jam dengan ukuran bola diperkecil menjadi $0,6 \mathrm{~cm}$. Serbuk hasil penggilingan Ball Milling akan dikarakterisasi menggunakan alat Scanning Electron Microscope (SEM) untuk melihat bentuk dan ukuran pada pasir besi dan alat X-Ray Fluorescence (XRF) untuk mengetahui kandungan pada pasir besi.

\section{HASIL DAN PEMBAHASAN}

\section{Suseptibilitas Magnetik}

Gambar 1 menunjukkan bahwa nilai suseptbilitas magnetik untuk sampel yang telah melalui proses Ball Milling berada dalam interval sebesar 69785,6 $\times 10^{-5}-88139,8$ $\times 10^{-5}$. Nilai suseptibilitas dari konsentrat 1 dan konsentrat 2 secara keseluruhan termasuk ilmenite (FeTiO3; anti-ferromagnetik) dalam interval 200-380.000 x $10^{-5}$ [11]. 


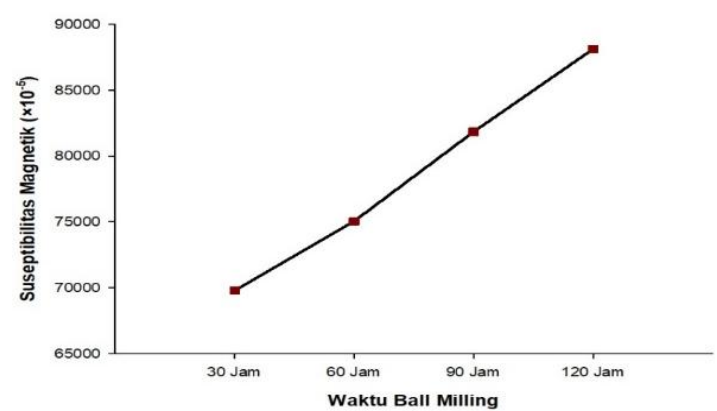

Gambar 1. Grafik hubungan antara nilai suseptibilitas magnetik setelah proses Ball Milling 8 A.

\section{Hasil Uji X-Ray Fluorescence (XRF)}

Identifikasi komposisi dari pasir besi dilakukan dengan menggunakan X-Ray Fluorescence (XRF) hasil ini ditampilkan pada Gambar 2. Identifikasi ini bertujuan untuk menentukan elemen-elemen yang terkandung pada sampel dan konsentrat, berikut adalah hasil identifikasi dari X-Ray Fluorescence (XRF).

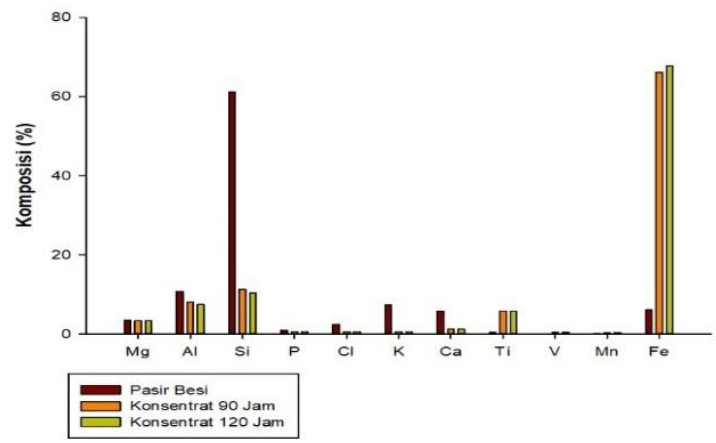

Gambar 2. Grafik elemen pada pasir Pantai Arta Pariaman Sumatera Barat sebelum dan sesudah di Ball Milling.

Hasil pengukuran X-Ray Flourescence (XRF) yang terlihat pada Gambar 2 menunjukkan bahwa perbedaan komposisi sebelum dan sesudah dilakukan Ball Milling yaitu adanya penambahan dan pengurangan dari elemen-elemen tertentu. Elemen $\mathrm{Si}$ mengalami penurunan setelah di Ball Milling yaitu dari $61,182 \%$ menjadi $10,415 \%$ dan peningkatan pada elemen $\mathrm{Fe}$ yang sangat signifikan yaitu dari $6,118 \%$ menjadi 67,746 $\%$. Peningkatan komposisi juga terjadi pada elemen-elemen lain seperti $\mathrm{Ti}, \mathrm{V}$ dan $\mathrm{Mn}$, peningkatan komposisi pada elemen ini menunjukkan bahwa bongkahan yang terdiri dari beberapa elemen magnetik dan nonmagnetik yang tergabung sudah terpisah dan elemen yang mengandung unsur magnetik didalamnya akan tertarik oleh magnet Niodinium Iron Boron $(\mathrm{NdFeB})$, sedangkan penurunan komposisi pada elemen lain disebabkan karena elemen tersebut merupakan pengotor yang sudah terpisah dari bongkahan yang terdiri dari unsur magnetik dan nonmagnetik [12].

\section{Hasil Uji Scanning Electron Microscope (SEM)}

Bentuk dan ukuran butiran konsentrat pasir besi setelah dilakukan penghancuran menggunakan teknik Ball Milling ditentukan dengan menggunakan Scanning Electron Microscope (SEM), dimana sampel pasir sebelum penghancuran berupa butiran-butiran kasar. Penghancuran ini bertujuan untuk memperoleh sampel yang lebih halus dan kandungan partikel magnetik yang lebih banyak. Hasil karakterisasi Scanning Electron Microscope (SEM) sampel pasir besi yang telah dihancurkan menggunakan Ball Milling dengan variasi 90 jam, dan 120 jam dengan perbesaran 1000 kali ditunjukkan pada Gambar 3 dan Gambar 4 sebagai berikut.

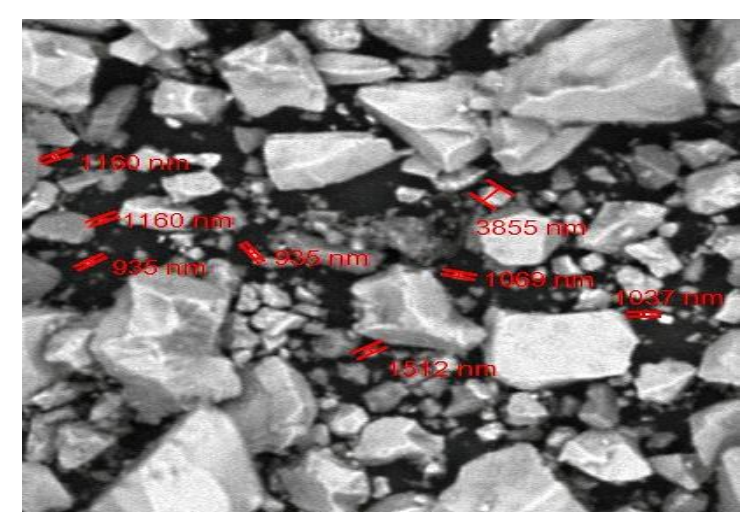

Gambar 3. Bentuk citra foto ukuran partikel di Ball Miling selama 90 jam

Gambar 3 dan Gambar 4 memperlihatkan hasil ukuran dan morfologi dari partikel pasir besi Pantai Arta Pariaman Sumatera Barat yang telah di Ball Milling selama 90 jam dan 120 jam menggunakan Scanning Electron 
Microscope (SEM), dimana dari gambar tersebut jelas bahwa hasil pengamatan mikrosruktur untuk sampel pasir besi memiliki morfologi permukaan yang sudah cukup halus dan bentuk partikelnya hampir bulat.

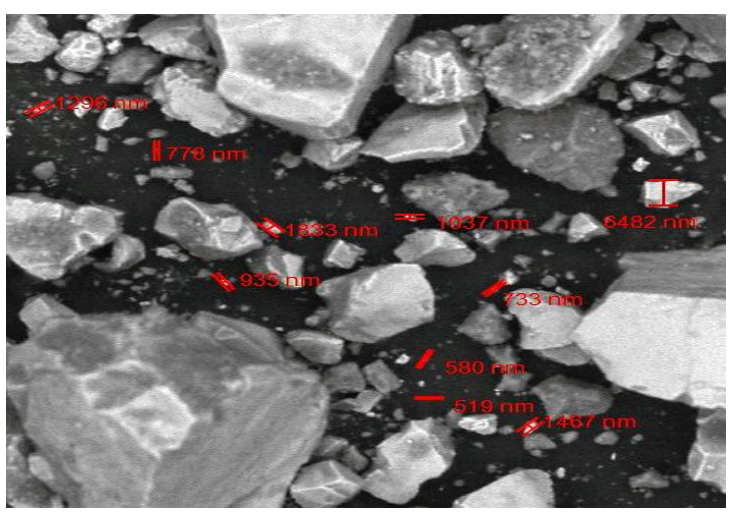

Gambar 4. Bentuk citra foto ukuran partikel di Ball Miling selama 120 jam

Hasil dari karakterisasi menggunakan alat Scanning Electron Microscope (SEM) pada Ball Milling selama 90 jam memiliki ukuran terkecil hingga $935 \mathrm{~nm}$ dan untuk Ball Milling selama 120 jam memiliki ukuran terkecil hingga $519 \mathrm{~nm}$. Ukuran partikel pasir besi hasil Ball Milling 90 jam dan 120 jam tidak mengalami banyak perubahan dalam ukuran karena bola-bola yang digunakan untuk Ball Milling lanjutan terlalu kecil maka bola-bola tersebut kehilangan energi sebelum saling bertumbukan karena terhambat oleh partikel pasir besi yang berada didalam tabung Ball Milling tersebut.

\section{KESIMPULAN}

Berdasarkan hasil penelitian yang telah dilakukan dan hasil perhitungan data maka dapat diambil kesimpulan sebagai berikut. Ball Milling merupakan metode yang efektif untuk memisahkan sebagian besar partikel magnetik dan non-magnetik dari pasir besi pada waktu maksimum 120 jam. Hasil dari karakterisasi Scanning Electron Microscope (SEM) memiliki ukuran partikel pasir besi dalam rentang sebesar $935 \mathrm{~nm}$ untuk waktu Ball Milling 90 jam dan ukuran dalam rentang sebesar $519 \mathrm{~nm}$ untuk waktu Ball Milling 120 jam. Sifat magnetik nilai suseptibilitas magnetik dan suseptibilitas massa jauh lebih besar dibandingkan sampel pasir besi sebelum Ball Milling sehingga partikel ini berada pada interval mineral ilmenite (FeTiO3; antiferromagnetik) dalam rentang 200$380.000 \times 10^{-5}$ untuk suseptibilitas magnetik dan $\quad(46-80000) \times 10^{-8} \mathrm{~m}^{3} / \mathrm{kg} \quad$ untuk suseptibilitas massa. Sampel yang telah melalui proses Ball Milling memiliki jumlah partikel besi (Fe) yang meningkat secara signifikan yaitu dari $6,118 \%$ menjadi $67,746 \%$ dilihat dari hasil uji X-Ray Fluorescence (XRF), Peningkatan ini sangat dipengaruhi oleh waktu lamanya penghancuran dan ukuran bola penumbuk pada proses Ball Milling.

\section{REFERENSI}

1. Yulianto, A., Bijaksana, S., \& Loeksmanto, W. (2002). Karakteristik Magnetik dari Pasir Besi Cilacap. Jurnal Fisika Himpunan Mahasiswa Fisika Indonesia, 5, 1-4.

2. Siregar, S. \& Arif, B. (2015). Penentuan Nilai Suseptibilitas Magnetk Mineral Magnetik Pasir Besi Sisa Pendulangan Emas di Kabupaten Sijunjung Sumatera Barat. Jurnal Fisika Unand, 4(4), 23028491.

3. Purwanto, S. (2008). Membangun Industri Komponen Bahan Magnetik Berbasis Sumber Daya Alam Lokal Melalui Sentuhan Nanoteknologi. Jurnal Riset industri, Pusat Teknologi Bahan Industri Nuklir-BATAN, 2(2), 107-113.

4. Yang, Y. X., Liu, M. L., Zhu, H., Chen, Y. R., Mu, G. J., Liu, X. N., \& Jia, Y. Q. (2008). Preparation, Characterization, Magnetic Property, and Mossbauer Spectra of the $\beta-\mathrm{FeOOH}$ Nanoparticles Modified by Nonionic Surfactant. Journal Magn. Mater., 320, 132-136.

5. Srivastava, M., Animesh, K., Ojha, S. C., Jay, S., Prashant, K. S., \& Avinash, C. P. (2010). Investigation on Magnetic of $\mathrm{Fe}_{2} \mathrm{O}_{3}$ Nanoparticles Synthesized under Surfactant-Free Condition by 
Hydrothermal Process. Journal of alloys and compounds, 500, 206.

6. Erwin \& Prayitno, A. (2017). Magnetic Exchange Interaction in Cobalt Samarium Thin Films for High Density Magnetic. Recording Media ARPN Journal of Engineering and Applied Sciences, 12(12), 3832.

7. Zeng, H., Jing, L., Liu, J. P., Zhong, L. W., \& Shouheng, S. (2002). ExchangeCoupled Nanocomposite Magnets by Nanoparticle Self-Assembly. Nature, 490, 395-398.

8. Mahmoudi, M., Shilpa, S., Ben, W., Shopie, L., \& Tapas, S. (2011). Superparamagentic Iron Oxide Nanoparticles (Spions) : Development, Surface Modification and Applications in Chemotherapy. Advanced drug delivery reviews, 63, 24-46.

9. Al-Saad, K. A., Amr, M. A., Hadi, D. T., Arar, R. S., Al-Sulaiti, M. M., Abdulmalik, T. A., Alsahamary, N. M., \&
Kwak, J. C. (2012). Iron Oxide Nanoparticles : Applicability for Heavy Metal Removal from Contaminated Water. Arab Journal of Nuclear Science and Applications, 45(2), 335-346.

10. Ihsan, Y. (2006). Rancangan Bangun dan Karakterisasi Ball Milling untuk Proses Penghancuran Serbuk Bahan Magnetik. Skripsi Fisika Medan Elektromagnet, Universitas Negeri Semarang.

11. Hunt, C. P., Moskowitz, B. M., \& Banerjee, S. K. (1995). Magnetic Properties of Rokcs and Minerals. Washington: American Geophysical Union.

12. Silaban, D. M., Erwin, Yanuar, Malik, U. (2017). Sifat Magnetik dan Mikrostruktur Endapan Pasir Besi Pantai Kata Pariaman Sumatera Barat. Prosiding Seminar Nasional Fisika ke2, Universitas Riau, Auditorium Hotel Ayola, Pekanbaru, 1 Oktober 2017, 142-145. 